Fixed Point Theory, 22(2021), No. 2, 871-880

DOI: $10.24193 /$ fpt-ro.2021.2.56

http://www.math.ubbcluj.ro/ nodeacj/sfptcj.html

\title{
RATE OF CONVERGENCE OF MODIFIED MANN ITERATION FOR ASYMPTOTICALLY NONEXPANSIVE MAPPINGS
}

\author{
YEKINI SHEHU \\ Department of Mathematics, Zhejiang Normal University, \\ Jinhua, 321004, People's Republic of China \\ E-mail: yekini.shehu@unn.edu.ng
}

\begin{abstract}
Modified Mann iteration has been studied extensively for the approximation of fixed points of asymptotically nonexpansive mappings by many authors and known to be weakly convergent in the infinite-dimensional space. Our aim in this present paper is to provide a nonasymptotic $O(1 / n)$ convergence rate result for a modified Mann iteration for asymptotically nonexpansive mappings in real Hilbert spaces.
\end{abstract}

Key Words and Phrases: Modified Mann iteration, asymptotically nonexpansive mappings, rate of convergence, Hilbert spaces.

2020 Mathematics Subject Classification: 49J53, 65K10, 49M37, 47H10.

\section{REFERENCES}

[1] S.C. Bose, Weak convergence to the fixed point of an asymptotically nonexpansive map, Proc. Amer. Math. Soc., 68(1978), no. 3, 305-308.

[2] M. Bravo, R. Cominetti, M. Pavez-Signé, Rates of convergence for inexact Krasnosel'skii-Mann iterations in Banach spaces, Math. Program., 175(2019), no. 1-2, Ser. A, 241-262.

[3] R. Bruck, T. Kuczumow, S. Reich, Convergence of iterates of asymptotically nonexpansive mappings in Banach spaces with the uniform Opial property, Colloq. Math., 65(1993), no. 2, 169-179.

[4] E. Casini, E. Maluta, Fixed points of uniformly Lipschitzian mappings in spaces with uniformly normal structure, Nonlinear Anal., 9(1985), no. 1, 103-108.

[5] S.S. Chang, J.Y. Park, J.Y. Cho, Iterative approximations of fixed points for asymptotically nonexpansive mappings in Banach spaces, Bull. Korean Math. Soc., 37(2000), no. 1, 109-119.

[6] C.E. Chidume, E.U. Ofoedu, H. Zegeye, Strong and weak convergence theorems for asymptotically nonexpansive mappings, J. Math. Anal. Appl., 280(2003), no. 2, 364-374.

[7] R. Cominetti, J.A. Soto, J. Vaisman, On the rate of convergence of Krasnoselski-Mann iterations and their connection with sums of Bernoullis, Israel J. Math., 199(2014), no. 2, 757-772.

[8] D. Davis, W. Yin, Convergence rate analysis of several splitting schemes, Splitting methods in communication, imaging, science, and engineering, 115-163, Sci. Comput., Springer, Cham, 2016.

[9] W.-Q. Deng, Strong convergence of Mann's type iteration method for an infinite family of generalized asymptotically nonexpansive nonself mappings in Hilbert spaces, Optim. Lett., 8(2014), no. $2,533-542$. 
[10] T. Dominguez-Benavides, M.A. Khamsi, S. Samadi, Asymptotically nonexpansive mappings in modular function spaces, J. Math. Anal. Appl., 265(2002), no. 2, 249-263.

[11] J. Garcia-Falset, B. Sims, M.A. Smyth, The demiclosedness principle for mappings of asymptotically nonexpansive type, Houston J. Math., 22(1996), no. 1, 101-108.

[12] K. Goebel, W.A. Kirk, A fixed point theorem for asymptotically nonexpansive mappings, Proc. Amer. Math. Soc., 35(1972), 171-174.

[13] J. Górnicki, Weak convergence theorems for asymptotically nonexpansive mappings in uniformly convex Banach spaces, Comment. Math. Univ. Carolin., 30(1989), no. 2, 249-252.

[14] J. Górnicki, Nonlinear ergodic theorems for asymptotically nonexpansive mappings in Banach spaces satisfying Opial's condition, J. Math. Anal. Appl., 161(1991), no. 2, 440-446.

[15] S.H. Khan, W. Takahashi, Approximating common fixed points of two asymptotically nonexpansive mappings, Sci. Math. Jpn., 53(2001), no. 1, 143-148.

[16] T.-H. Kim, H.-K. Xu, Remarks on asymptotically nonexpansive mappings, Nonlinear Anal., 41(2000), no. 3-4, Ser. A: Theory Methods, 405-415.

[17] G. Li, B. Sims, Fixed point theorems for mappings of asymptotically nonexpansive type, Nonlinear Anal., 50(2002), no. 8, Ser. A: Theory Methods, 1085-1091.

[18] J. Liang, J. Fadili, G. Peyré, Convergence rates with inexact non-expansive operators, Math. Program., 159(2016), no. 1-2, Ser. A, 403-434.

[19] T.-C. Lim, H.K. Xu, Fixed point theorems for asymptotically nonexpansive mappings, Nonlinear Anal., 22(1994), no. 11, 1345-1355.

[20] P.-K. Lin, K.-K. Tan, H.K. Xu, Demiclosedness principle and asymptotic behavior for asymptotically nonexpansive mappings, Nonlinear Anal., 24(1995), no. 6, 929-946.

[21] S.-Y. Matsushita, On the convergence rate of the Krasnoselski-Mann iteration, Bull. Aust. Math. Soc., 96(2017), no. 1, 162-170.

[22] Z. Opial, Weak convergence of the sequence of successive approximations for nonexpansive mappings, Bull. Amer. Math. Soc., 73(1967), 591-597.

[23] M.O. Osilike, S.C. Aniagbosor, Weak and strong convergence theorems for fixed points of asymptotically nonexpansive mappings, Math. Comput. Modelling, 32(2000), no. 10, 1181-1191.

[24] B.E. Rhoades, Fixed point iterations for certain nonlinear mappings, J. Math. Anal. Appl., 183(1994), no. 1, 118-120.

[25] J. Schu, Weak and strong convergence to fixed points of asymptotically nonexpansive mappings, Bull. Austral. Math. Soc., 43(1991), no. 1, 153-159.

[26] J. Schu, Iterative construction of fixed points of asymptotically nonexpansive mappings, J. Math. Anal. Appl., 158(1991), no. 2, 407-413.

[27] K.-K. Tan, H.K. Xu, Fixed point iteration processes for asymptotically nonexpansive mappings, Proc. Amer. Math. Soc., 122(1994), no. 3, 733-739.

[28] L. Wang, Strong and weak convergence theorems for common fixed point of nonself asymptotically nonexpansive mappings, J. Math. Anal. Appl., 323(2006), no. 1, 550-557.

[29] Q. Yan, G. Cai, Convergence analysis of modified viscosity implicit rules of asymptotically nonexpansive mappings in Hilbert spaces, Rev. R. Acad. Cienc. Exactas Fís. Nat. Ser. A Mat. RACSAM, 112(2018), no. 4, 1125-1140.

Received: March 14, 2019; Accepted: May 30, 2019. 